\title{
Estimation of daily cadmium intake from cadmium in blood or cadmium in urine
}

\author{
Masayuki Ikeda $^{1} \cdot$ Haruo Nakatsuka ${ }^{2} \cdot$ Takao Watanabe $^{3} \cdot$ Shinichiro Shimbo $^{4}$
}

Received: 22 April 2015/Accepted: 2 July 2015/Published online: 15 July 2015

(C) The Japanese Society for Hygiene 2015

\begin{abstract}
Objectives It would be quite convenient if daily dietary cadmium intake (Cd-D) can be estimated either from $\mathrm{Cd}$ in blood $(\mathrm{Cd}-\mathrm{B})$ or from $\mathrm{Cd}$ in urine $(\mathrm{Cd}-\mathrm{U})$. The aim of the study was to examine if $\mathrm{Cd}-\mathrm{D}$ can be estimated from $\mathrm{Cd}-\mathrm{B}$ or Cd-U.

Methods The data available in a previous publication were employed for regression analyses between Cd-D and Cd-B, and between Cd-D and Cd-U. 30 sites in various prefectures throughout Japan were surveyed and 20 adult women/site on average provided food duplicate, peripheral blood, and second morning urine samples. Geometric means were taken as representative values and employed in regression analyses.

Results $\mathrm{Cd}-\mathrm{D}, \mathrm{Cd}-\mathrm{B}$, and $\mathrm{Cd}-\mathrm{U}_{\mathrm{cr}}$ [i.e., $\mathrm{Cd}-\mathrm{U}$ after correction for creatinine (cr) concentration] distributed in ranges of $12.5-70.5 \mu \mathrm{g} / \mathrm{day}, \quad 0.46-3.98 \mu \mathrm{g} / \mathrm{l}$, and $1.16-11.02 \mu \mathrm{g} / \mathrm{g}$ cr, respectively. A close correlation was observed between Cd-D and Cd-B, and also between Cd-D and $\mathrm{Cd}-\mathrm{U}_{\mathrm{cr}}$ with $r=0.76$ and $r=0.79(p<0.001$ for both), respectively. Both regression lines passed close to the origins. Application of $1.23 \mu \mathrm{g} \mathrm{Cd} / \mathrm{l}$ blood and $1.26 \mu \mathrm{g}$ $\mathrm{Cd} / \mathrm{g} \mathrm{cr}$ in urine (average levels for adult Japanese women) to the regression equations gave 16.5 and $11.5 \mu \mathrm{g} \mathrm{Cd} / \mathrm{day}$.
\end{abstract}

Masayuki Ikeda

m-71-ikeda@nifty.com

Kyoto Industrial Health Association, Kyoto 604-8472, Japan

2 School of Nursing, Miyagi University, Taiwa-cho 981-3298, Japan

3 Department of Childhood Education, Faculty of Human Sciences, Tohoku Bunkyo University, Yamagata 990-2316, Japan

4 Kyoto Women's University, Kyoto 605-8501, Japan
Conclusions The analyses suggested that it may be possible to estimate Cd-D from Cd-B or Cd-U. Cd-B-based estimation should be more respected. As variations in the estimation parameters and estimated values are inherent to field surveys, care should be taken in the application of the study results. Application on a group basis (and not on an individual basis) should be considered.

Keywords Cadmium in blood C Cadmium in urine . Dietary cadmium intake $\cdot$ Estimation · Japan

\section{Introduction}

Cadmium (Cd) is a well-studied environmental pollutant with insidious toxicities on the kidney and then the bone [1, 2]. Elevated dietary $\mathrm{Cd}$ intake has been a long-standing environmental concern in Japan [3, 4], primarily because $\mathrm{Cd}$ contents in rice harvested in Japan is high $[5,6]$ as compared with the levels in rice from other countries, whereas boiled rice is a historical staple food for general populations [7]. It is noted that Cd-D has been gradually decreasing in the recent years $[3,8]$, e.g., $>50 \mu \mathrm{g} /$ day in late $1960 \mathrm{~s},<50 \mu \mathrm{g} /$ day in $1970 \mathrm{~s}$, and about $30 \mu \mathrm{g} /$ day in 1980s [3]. The other report indicated that Cd-D was $45-50 \mu \mathrm{g}$ /day in late 1970s, and then decreased gradually to reach $20-25 \mu \mathrm{g} /$ day in 2004 and 2005 [8]. High Cd-D, however, remains as a matter worthy of attention [8].

For determination of dietary $\mathrm{Cd}$ intake, food duplicate sample collection [9] followed by blending, wet-digestion, and graphite furnace atomic absorption spectrometry (or inductively coupled plasma mass spectrometry) is a reliable method [10], but the procedures are quite hand-consuming and nerve-taxing first of all to sample donors and also to the analytical chemists. 
Based on the statistical analyses of existing data on $\mathrm{Cd}$ in whole-day food duplicate samples (Cd-D), $\mathrm{Cd}$ in urine after correction for urinary creatinine concentration $(\mathrm{Cd}-$ $\mathrm{U}_{\mathrm{cr}}$ ), and $\mathrm{Cd}$ in peripheral blood (Cd-B) [11], a successful trial was made in this study group to establish equations which allow estimation of Cd-D from Cd-B as well as from $\mathrm{Cd}-\mathrm{U}_{\mathrm{cr}}$. The results were presented in this short communication.

\section{Materials and methods}

Data on $\mathrm{Cd}-\mathrm{D}, \mathrm{Cd}-\mathrm{B}$, and $\mathrm{Cd}-\mathrm{U}_{\mathrm{cr}}$ were cited from Ikeda et al. [11]. The data were based on the field surveys in 30 sites distributed throughout Japan from northern-most Hokkaido Island to the southern-most Okinawa Islands, and 20 adult women/site on average participated in the study by offering food duplicate, peripheral blood, and second morning urine samples. Geometric mean values (GMs) were taken to represent each study site. The GM values were in a range of $12.5-70.5 \mu \mathrm{g} /$ day for $\mathrm{Cd}-\mathrm{D}$, 0.46-3.98 $\mu \mathrm{g} / \mathrm{l}$ for $\mathrm{Cd}-\mathrm{B}$, and 1.1-11.02 $\mu \mathrm{g} / \mathrm{g}$ cr for $\mathrm{Cd}-\mathrm{U}_{\mathrm{cr}}$.

The GM values were subjected to linear regression analyses between Cd-D and Cd-B and between Cd-D and $\mathrm{Cd}-\mathrm{U}_{\mathrm{cr}}$. Equations for regression lines and the $95 \%$ upper and lower limit curves were calculated with a software 'Excel Statistics' [12]. Comparison of two regression lines in terms of slopes, intercepts, and correlation coefficients was conducted by analysis of covariance after Ichihara [13].

\section{Results and discussion}

The results of regression analyses were depicted in Fig. 1[(a) for Cd-B vs. Cd-D and (b) for Cd-U $\mathrm{Cr}_{\mathrm{cr}}$ vs. Cd-D] for visual understanding of close correlation between the paired parameters. Equations for regression lines (Eqs. 2, 5) and the $95 \%$ upper and lower limit curves (Eqs. 1, 3, 4, and 6) were given in the top 2nd-7th lines (the 1991-1997 survey) in Table 1 . It was clear that $\mathrm{Cd}-\mathrm{D}$ increased as a linear function of the increase in $\mathrm{Cd}-\mathrm{B}$ and also in $\mathrm{Cd}-\mathrm{U}_{\mathrm{cr}}$. The correlation coefficients were $>0.7$ and $p<0.001$ for both cases. However, variations around the regression lines were also noted.

To the knowledge of the authors, this is the first successful trial to develop the equations for estimating dietary $\mathrm{Cd}$ intake from $\mathrm{Cd}$ levels in blood or urine for Japanese populations. As the procedures for food duplicate sampling (followed by instrumental analyses) are complex, the CdB- or Cd-U-based estimation of Cd-D will be a practical and convenient measure in $\mathrm{Cd}$ burden study, as $\mathrm{Cd}-\mathrm{B}$ and $\mathrm{Cd}-\mathrm{U}$ have been commonly measured $[1,2]$. The present
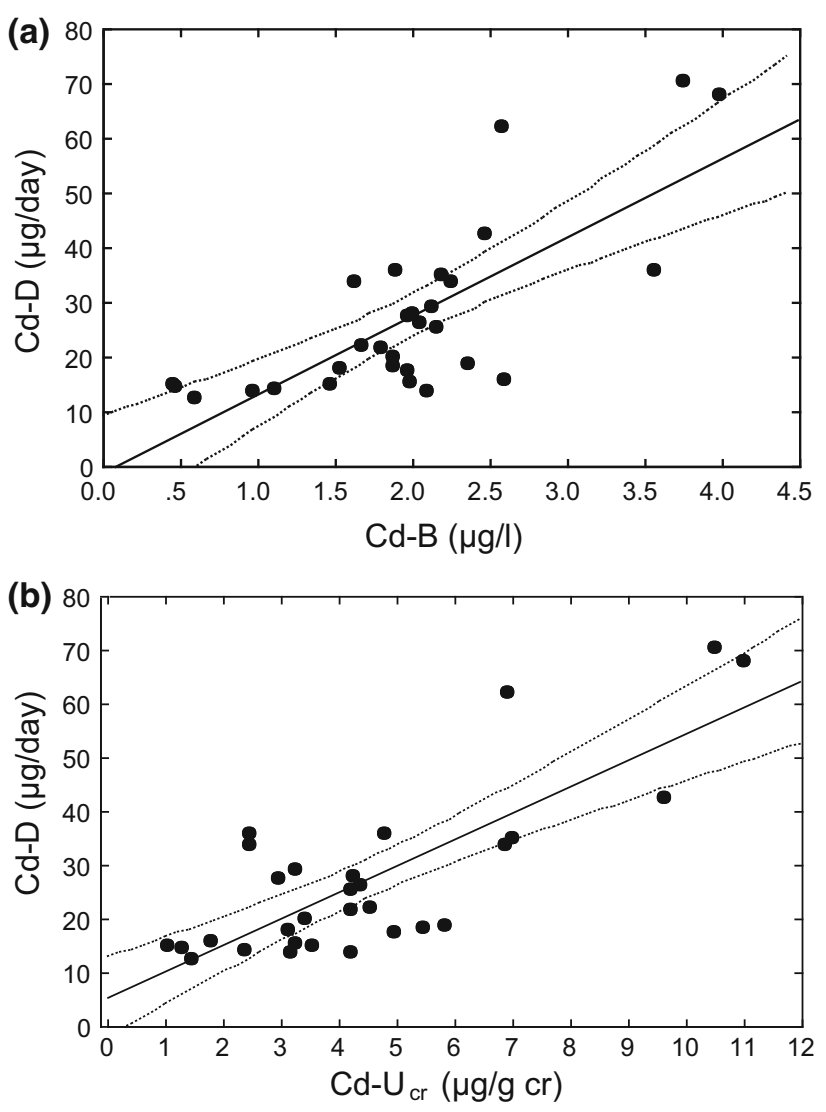

Fig. 1 Linear correlation of $\mathrm{Cd}$ in blood and $\mathrm{Cd}$ in urine (as corrected for creatinine concentration) with $\mathrm{Cd}$ in daily diet; the 1991-1997 survey [11]. The line in the middle is a calculated regression line. The two curves on both sides show the $95 \%$ upper and lower limits. Each $\operatorname{dot}(n=30)$ represent one survey site. a Cadmium in blood (Cd-B) versus cadmium in daily diet (Cd-D). b Cadmium in urine as corrected for creatinine concentration $\left(\mathrm{Cd}-\mathrm{U}_{\mathrm{cr}}\right)$ versus cadmium in daily diet (Cd-D)

analyses are based on the results from surveys in adult Japanese women, but the equations in Table 1 may be also applicable to other rice-depending populations in East and South-East Asia. A preliminary analysis of Cd-D and Cd$\mathrm{U}_{\mathrm{cr}}$ data from rice-depending areas in Asia [14] gave a regression line between $\mathrm{Cd}-\mathrm{D}$ and $\mathrm{Cd}-\mathrm{U}_{\mathrm{cr}}$ with statistically no significant $(p<0.05)$ difference from the regression line in Table 1 (data not shown). Analyses on the relationship between $\mathrm{Cd}-\mathrm{D}$ and $\mathrm{Cd}-\mathrm{B}$ (in addition to $\mathrm{Cd}-\mathrm{U}$ ) are envisaged. Further studies are also desirable on the applicability of the present results to rice non-depending populations who depend on, e.g., wheat and other cereals as staple food.

With regard to the choice of $\mathrm{Cd}-\mathrm{B}$ or $\mathrm{Cd}-\mathrm{U}$, repeated measurement of $\mathrm{Cd}-\mathrm{B}$ and $\mathrm{Cd}-\mathrm{U}$ was conducted with participation of five adult women volunteers to compare stability of the two exposure parameters. Thus, urine samples were collected once a month for 12 times, and peripheral blood was sampled once every 3 months for four times. 
Table 1 Equations for regression lines and confidence ranges

\begin{tabular}{|c|c|c|c|c|c|c|}
\hline Survey & $\mathrm{X}$ & $\mathrm{Y}$ & Type $^{\mathrm{a}}$ & Equation & & \\
\hline \multicolumn{7}{|c|}{ The 1991-1997 survey $(n=30)$} \\
\hline & Cd-B & Cd-D & $95 \% \mathrm{UL}$ & $\mathrm{Y}=+10.18+7.19 \mathrm{X}+1.772 \mathrm{X}^{2}$ & & Eq. 1 \\
\hline & $(\mu \mathrm{g} / \mathrm{l})$ & ( $\mu \mathrm{g} /$ day) & RL & $\mathrm{Y}=-1.13+14.36 \mathrm{X}$ & $r=0.76^{\mathrm{b}}$ & Eq. 2 \\
\hline & & & $95 \% \mathrm{LL}$ & $\mathrm{Y}=-12.43+21.54 \mathrm{X}-1.772 \mathrm{X}^{2}$ & & Eq. 3 \\
\hline & $\mathrm{Cd}-\mathrm{U}_{\mathrm{cr}}$ & Cd-D & $95 \% \mathrm{UL}$ & $\mathrm{Y}=+12.84+3.33 \mathrm{X}+0.169 \mathrm{X}^{2}$ & & Eq. 4 \\
\hline & $(\mu \mathrm{g} / \mathrm{g} \mathrm{cr})$ & ( $\mu \mathrm{g} /$ day) & RL & $\mathrm{Y}=+5.35+4.90 \mathrm{X}$ & $r=0.79^{\mathrm{b}}$ & Eq. 5 \\
\hline & & & $95 \% \mathrm{LL}$ & $Y=-2.13+6.48 X-0.169 X^{2}$ & & Eq. 6 \\
\hline \multicolumn{7}{|c|}{ The $1977-1981$ survey $(n=18)$} \\
\hline & Cd-B & Cd-D & $95 \% \mathrm{UL}$ & $\mathrm{Y}=+33.88-6.45 \mathrm{X}+3.214 \mathrm{X}^{2}$ & & \\
\hline & $(\mu \mathrm{g} / \mathrm{l})$ & ( $\mu \mathrm{g} /$ day) & RL & $Y=-20.32+17.52 X$ & $r=0.68^{\mathrm{c}}$ & \\
\hline & & & & $Y=-74.53+41.49 X-3.214 X^{2}$ & & \\
\hline
\end{tabular}

When GM values were compared (i.e., $12 \mathrm{GMs}$ for $\mathrm{Cd}-\mathrm{U}_{\mathrm{cr}}$ and 4 GMs for Cd-B), the highest and the lowest GM for Cd- $\mathrm{U}_{\mathrm{cr}}$ were 3.9 and $2.0 \mu \mathrm{g} / \mathrm{g}$ cr, respectively (with the highest/lowest ratio of 1.9), whereas 3.3 and $2.9 \mu \mathrm{g} / \mathrm{l}$ for Cd-B (the ratio: 1.1) [15], indicating better stability for Cd$\mathrm{B}$ than for $\mathrm{Cd}-\mathrm{U}$. This observation may suggest that more care should be practiced in using $\mathrm{Cd}-\mathrm{U}_{\mathrm{cr}}$ (rather than $\mathrm{Cd}-\mathrm{B}$ ) to estimate $\mathrm{Cd}-\mathrm{D}$, as the estimate based on better stabilized parameter should be more respected.

Retrieval through published literatures revealed that data on Cd-D coupled with $\mathrm{Cd}-\mathrm{B}$ or $\mathrm{Cd}-\mathrm{U}$ were very few possibly due to the complexity of the procedures for food duplicate collection and analyses, as described above. Thus, the data for validation of the proposed equations (top 7 lines in Table 1) are limited. This study group conducted field surveys on $\mathrm{Cd}$ exposure of adult women also in 1977-1981, and Watanabe et al. [16] published GM values for Cd-D in combination with Cd-B in 18 locations. It should be noted that the GM Cd-D, $37.0 \mu \mathrm{g} /$ day [16] in 1977-1981, was substantially higher than the levels, $24.7 \mu \mathrm{g} /$ day [11] in 1991-1997. For validation purpose, Cd-B and Cd-D correlation was analyzed in a manner similar to the present study. The results are presented in the bottom 4 lines (the 1977-1981 survey) in Table 1 and graphically presented in Fig. 2. Although the regression line for the 1977-1981 survey apparently had a steeper slope and a lower intercept than the line for the 1991-1997 survey, further statistical analysis showed that there was no significant difference $(p>0.05)$ between the pairs of the intercepts, the slopes, and the correlation coefficients, which may suggest reproducibility of the present study results.

Horiguchi et al. [4] conducted a mass analysis for Cd-B and $\mathrm{Cd}-\mathrm{U}_{\mathrm{cr}}$ in five locations in Japan, with 1380

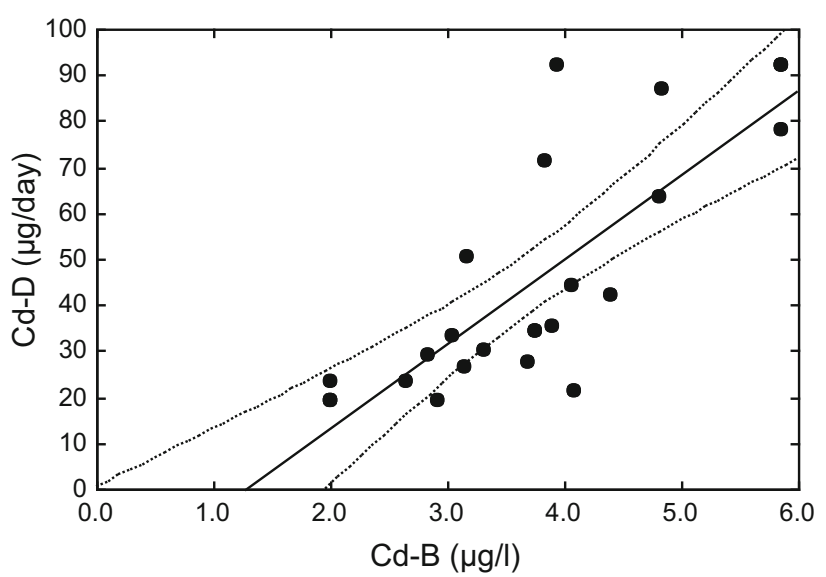

Fig. 2 Linear correlation of $\mathrm{Cd}$ in blood with $\mathrm{Cd}$ in daily diet; the 1977-1981 survey [16]. Notes are as under Fig. 1 except $n=18$

participating women in total. For Cd-D, they measured $\mathrm{Cd}$ intake through boiled rice consumption (Cd-rice). From Cd-rice, Cd-D was estimated with two separate assumptions, i.e., assumption $\mathrm{A}$ was such that $\mathrm{Cd}-\mathrm{D}$ was twice the Cd-rice [meaning that the same amount of $\mathrm{Cd}$ came from rice and from foods (and water) other than rice], and assumption $\mathrm{B}$ was such that $15 \mu \mathrm{g} \mathrm{Cd}$ was expected to come from foods (and water) other than rice (irrespective of individuals and survey sites). GM values for Cd-D with assumption A were in a range of 6.99-51.99 $\mu \mathrm{g} /$ day. With assumption $\mathrm{B}$, the $\mathrm{GM}$ values distributed from 19.88 to $44.07 \mu \mathrm{g} /$ day. GM Cd-B and GM Cd- $\mathrm{U}_{\mathrm{cr}}$ were in ranges of $1.65-3.61 \mu \mathrm{g} / \mathrm{l}$ and $2.63-4.08 \mu \mathrm{g} / \mathrm{g} \mathrm{cr}$, respectively [4]. Application of the reported $\mathrm{Cd}-\mathrm{B}$ and $\mathrm{Cd}-\mathrm{U}_{\mathrm{cr}}$ values to Eqs. 2 and 5 (Table 1) gave $34.8 \pm 11.2 \mu \mathrm{g} /$ day (AM \pm ASD) in a range of $24.8-53.0$ and $21.5 \pm 2.6 .2 \mu \mathrm{g} /$ day 
$(\mathrm{AM} \pm \mathrm{ASD})$ in a range of 18.2-25.3 $\mu \mathrm{g} / \mathrm{day}$, respectively. Statistical analysis by paired $t$ test showed no significant difference $(p>0.10)$ between Cd-B-based Cd-D estimation and assumption A-based Cd-D, and also between $\mathrm{Cd}-$ B-based Cd-D estimation and assumption B-based Cd-D. It was also the case when $\mathrm{Cd}-\mathrm{U}_{\mathrm{cr}}$-based Cd-D estimation was compared with assumption A-based Cd-D. However, a difference was significant $(p<0.05)$ between $\mathrm{Cd}-\mathrm{U}_{\mathrm{cr}^{-}}$ based Cd-D estimation and assumption B-based Cd-D. In short, Cd-B-based estimation gave reliable estimate (better than $\mathrm{Cd}-\mathrm{U}_{\mathrm{cr}}$-based one) [4], in agreement with the observation that $\mathrm{Cd}-\mathrm{B}$ is a more stable parameter that $\mathrm{Cd}-\mathrm{U}$ [15].

With regard to possible confounders, smoking cigarettes is a known non-occupational $\mathrm{Cd}$ source for general populations. It was observed that daily consumption of 6-10 cigarettes may induce $0.6 \mu \mathrm{g} \mathrm{Cd} / 1$ urine [17] (which should be roughly equivalent to $0.6 \mu \mathrm{g} / \mathrm{g} \mathrm{cr}$, when creatinine concentration is assumed to be about $1 \mathrm{~g} / \mathrm{l}$ in women [18]). Therefore, the effect on Cd-D versus $\mathrm{Cd}-\mathrm{U}_{\text {cr }}$ relationship should be minimal.

Application of Cd-B of $1.23 \mu \mathrm{g} / \mathrm{l}$ (the average Cd-B for adult Japanese women population in 2003-2011 [13] ) to the Eq. 2 in Table 1 gave $16.5 \mu \mathrm{g} / \mathrm{day}$ as the Cd-B-based best estimate for Cd-D in recent years (i.e., around 2003-2011). It was also possible to estimate Cd-D based on Cd- $\mathrm{U}_{\mathrm{cr}}$ (Eq. 5 in Table 1), taking the national average of $1.26 \mu \mathrm{g} / \mathrm{g}$ cr for adult women with no known specific $\mathrm{Cd}$ exposures [18]. The calculation gave 16.5 and $11.5 \mu \mathrm{g} /$ day, respectively. Regarding variations when the same estimating parameter is used, the application of these Cd-B and $\mathrm{Cd}-\mathrm{U}_{\mathrm{cr}}$ values to Eqs. 1 and 3 or Eqs. 4 and 6 gave $95 \%$ estimation ranges for Cd-D of 11.4-21.7 and $5.8-17.3 \mu \mathrm{g} / \mathrm{day}$, respectively. There was a substantial over-up between the two ranges, but about $40 \%$ difference was noted between the two estimates of 11.5 and $16.5 \mu \mathrm{g}$ $\mathrm{Cd} /$ day. Nevertheless, the level of $11.5-16.5 \mu \mathrm{g} \mathrm{Cd} /$ day may suggest a gradual decrease in Cd-D as compared with the levels of 20-40 $\mu \mathrm{g} /$ day in 1980s-1990s [3].

There are several limitations in the present analysis. First of all, the database employed [11] was more than 10 years old. Literature survey revealed that no later data are available in which $\mathrm{Cd}-\mathrm{B}$ or $\mathrm{Cd}-\mathrm{U}$ was examined together with Cd-D as stated previously, although reliable and convenient methods for Cd-D estimation are ever requested.

The number of sites surveyed was limited to 30 locations and the numbers of participants were 20 subjects/site on average [11]. Possibly due to such limitation at least in part, variation around the regression lines was noted although the correlation between pairs of parameters (i.e., Cd-B vs. Cd-D and Cd- $\mathrm{U}_{\mathrm{cr}}$ vs. Cd-D) was highly significant $(p<0.001)$. Thus, the variation range for estimated Cd-D was still substantial as discussed above.
Such variation in the estimating parameters as well as the estimated values may be inherent to field surveys, and care should be taken in the application of the study results. One of the counter measures would be the use of a representative value, e.g., GM in case of $\mathrm{Cd}-\mathrm{B}$ and $\mathrm{Cd}-\mathrm{U}$ (and a median would be close to GM). A recommended procedure therefore will be the application of the equation only on a group basis, e.g., application of geometric mean values, and not individual measures.

The present analyses were based on the observation from non-polluted areas where Cd-B was $<4.0 \mu \mathrm{g} / \mathrm{l}$ or $\mathrm{Cd}-$ $\mathrm{U}_{\mathrm{cr}}$ was $<11 \mu \mathrm{g} / \mathrm{g}$ cr (Fig. 1). Applicability of the Eqs. 2 and 5 (Table 1) to the groups from polluted areas with higher $\mathrm{Cd}-\mathrm{D}$ is an important question from a practical view point. Further studies are apparently necessary and no answer is currently available. With this regard, Hara et al. [19] conducted a survey in a Cd-polluted area and reported a very high Cd-D of $205.7 \mu \mathrm{g} / \mathrm{day}$, whereas Saito et al. [20] reported that $\mathrm{Cd}-\mathrm{U}$ for women was $8.6 \mu \mathrm{g} / \mathrm{l}$. Both values were assumedly arithmetic means. Only 10 Cd-D measurements were conducted whereas 154 women offered urine samples, and therefore questions may remain on the representativeness of the Cd-D values for total participants. In addition, it was not clear whether the food duplicate samples were for men or for women; it is known that Cd-D may differ between men and women, and is greater for men than for women [21] possibly because men used to take more rice than women. Nevertheless, a large difference between the reported Cd-D (205.7 $\mu \mathrm{g} /$ day) and Eq. 5-based estimate of $47.5 \mu \mathrm{g} /$ day suggests that the relation between $\mathrm{Cd}-\mathrm{U}$ and $\mathrm{Cd}-\mathrm{D}$ may be different when the dietary $\mathrm{Cd}$ exposure is very high and therefore Eq. 5 may not be applicable to the cases where Cd-D is high due to pollution with Cd. In 2008, the Food Safety Committee, Japan, reported a tolerable weekly intake (TWI) of $7 \mu \mathrm{g} / \mathrm{kg}$ body weight/week to the Minister of Health, Labour and Welfare [8]. In practice, the present study results may not be applicable to the populations for whom the GM Cd-D is in excess of the TWI. Assuming that the average body weight for adult Japanese population is about $60 \mathrm{~kg}$ [7], the TWI when calculated for daily intake basis would be about $60 \mu \mathrm{g} / \mathrm{day}$. Application of this value to Eqs. 3 and 5 in Table 1 gives $4.3 \mu \mathrm{g} / \mathrm{l}$ for Cd-B and $11.2 \mu \mathrm{g} / \mathrm{g}$ cr for $\mathrm{Cd}-\mathrm{U}_{\mathrm{cr}}$ as possible critical values for exclusion. Nevertheless, further studies are apparently envisaged to validate the applicability of this TWI value as the exclusion criterion.

Acknowledgments The authors are grateful to Dr. T. Kawai of Osaka Occupational Health Service Center, Osaka, Japan for his technical support to this study.

Conflict of interests The authors declare that they have no conflicts of Interest. 


\section{References}

1. International Programme on Chemical Safety (IPCS). Environmental health criteria I34. Cadmium. Gcneva: World Health Organization; 1992.

2. Internatlional Programme on Chemical Safety (IPCS). Envrronmenttal health criteria 135. Cadmium-environmental aspects. Geneva: World Health Organization; 1992.

3. Ikeda M, Ezaki T, Tsukahara T, Moriguchi J. Dietary cadmium intake in polluted and non-polluted areas in Japan in the past and in the present. Int Arch Occup Environ Health. 2004;77:227-34.

4. Horiguchi H, Oguma E, Sasaki S, Okubo H, Murakami K, Miyamoto K, et al. Age-relevant renal effects of cadmium exposure through consumption of home-harvested rice in female Japanese farmers. Environ Int. 2013;56:1-9.

5. Watanabe T, Shimbo S, Moon C-S, Zhang Z-W, Ikeda M. Cadmium contents in rice samples from various areas in the world. Sci Total Environ. 1996;184:191-6.

6. Shimbo S, Zhang Z-W, Watanabe T, Nakatsuka H, MatsudaInoguchi N, Higashikawa K, et al. Cadmium and lead contents in rice and other cereal products in Japan in 1998-2000. Sci Total Environ. 2001;281:165-75.

7. National Institute of Health and Nutrition, Japan. The National Health and Nutrition Survey, 2011. Tokyo: Daiichi Shuppann Publishers; 2015. p. 68-71.

8. Food Safety Committee, Japan. Document on safety of dietary cadmium intake, attached to the report to the Minster of Health, Labour and Welfare, Japan. 2008.

9. Acheson KJ, Campbell IT, Edholm OG, Miller DS, Stock MJ. The measurement of food and energy intake in man-an evaluation of some techniques. Am J Clin Nutr. 1980;33:1147-54.

10. Ikeda M, Ohashi F, Fukui Y, Sakuragi S, Moriguchi J. Cadmium, chromium, lead, manganese and nickel concentrations in blood of women in non-polluted areas in Japan, as determined by inductively coupled plasma-sector field-mass spectrometry. Int Arch Occup Environ Health. 2011;84:139-50.

11. Ikeda M, Zhang Z-W, Moon C-S, Shimbo S, Watanabe T, Nakatsuka $\mathrm{H}$, et al. Possible effects of environmental cadmium exposure on kidney function in the Japanese general population. Int Arch Occup Environ Health. 2000;73:15-25.

12. Esumi \& Co. EXCEL STATISTICS. Tokyo (Japan).

13. Ichihara K. Statistics for Bioscience. Tokyo (Japan): Nankodo Publishers; 1990; (in Japanese).

14. Ikeda M, Zhang Z-W, Shimbo S, Watanabe T, Nakatsuka H, Moon C-S, et al. Urban population exposure to lead and cadmium in east and south-east Asia. Sci Total Environ. 2000;249:373-84.

15. Yamagami T, Suna T, Fukui Y, Ohashi F, Takada S, Sakurai H, et al. Biological variations in $\alpha_{1}$-microglobulin, $\beta_{2}$-microglobulin and $N$-acetyl- $\beta$-D-glucosaminidase in adult women in a nonpolluted area. Int Arch Occup Environ Health. 2008;81:263-71.

16. Watanabe T, Nakatsuka H, Shimbo S, Iwami O, Imai Y, Moon $\mathrm{C}-\mathrm{S}$, et al. Reduced cadmium and lead burden in Japan in the past 10 years. Int Arch Occup Environ Health. 1996;68:305-14.

17. Ikeda M, Moriguchi J, Ezaki T, Fukui Y, Ukai H, Okamoto S, et al. Smoking-induced increase in urinary cadmium levels among Japanese women. Int Arch Occup Environ Health. 2005;78:533-40.

18. Ezaki T, Tsukahara T, Moriguchi J, Furuki K, Fukui Y, Ukai H, et al. No clear-cut evidence for cadmium-induced tubular dysfunction among over 10,000 women in the Japanese general population; a nationwide large-scale survey. Int Arch Occup Environ Health. 2003;76:186-96.

19. Hara Y. Part 1. General view. In: Saito H, Tskebayashi S, Harada $\mathrm{K}$, Hara Y, editors. Chronic cadmium poisoning. Nagasaki: Nagasaki University School of Medicine (the "n department of Medicine); 2013. p. 42 (in Japanese).

20. Saito H. Part 2. Health survey on residents. In: Saito H, Tskebayashi S, Harada K, Hara Y, editors. Chronic cadmium poisoning. Nagasaki: Nagasaki University School of Medicine (the "n department of Medicine); 2013. p. 56; (in Japanese).

21. Watanabe T, Koizumi A, Fujita H, Kumai M, Ikeda M. Dietary cadmium intakes of farmers in nonpolluted areas in Japan, and the relation with blood cadmium levels. Environ Res. 1985;37:33-43. 